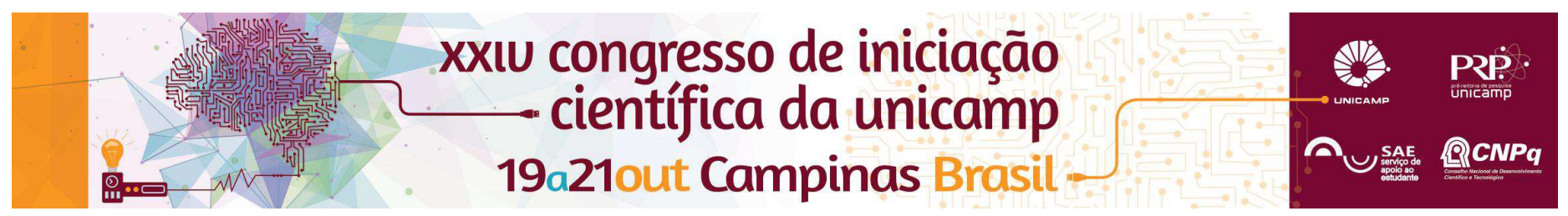

\title{
Métodos Não Destrutivos utilizados na Classificação da Madeira, na Caracterização de Materiais e na Tomografia Ultrassônica
}

\author{
Jéssica S. Neves, Mônica Ruy, Rafael Mansini, Cinthya Bertoldo, Raquel Gonçalves
}

\section{Resumo}

O desenvolvimento de pesquisas utilizando tecnologias não destrutivas para a caracterização, a classificação e a inspeção de materiais de construção pelo Laboratório de Ensaios na Destrutivos (LabEND) da Feagri unido com a necessidade da inserção de estudantes de escolas públicas de ensino médio em ambiente científico e universitário deu origem a esse projeto, que teve como objetivo incorporar esses alunos em atividades do grupo de pesquisa. $O$ projeto possibilitou a convivência do bolsista com docentes e alunos da Faculdade de Engenharia Agrícola e abriu porta para conhecimentos científicos. O bolsista passou por treinamentos para utilização de equipamentos de ultrassom e pôde utilizar esses conhecimentos no auxílio durante a realização de ensaios para caracterização e classificação de materiais, e na geração de imagens de ultrassom para a inspeção e avaliação de árvores. Como resultado desse projeto destaca-se o crescimento pessoal e profissional do bolsista, e sua inserção em âmbito científico universitário.

Palavras-chave: Materiais de construção, ultrassom, inspeção

\section{Introdução}

Sabendo-se da importância da inserção de alunos de ensino médio no ambiente da universidade, a proposta desse projeto de Iniciação Científica EM foi de envolver esses alunos em atividades de um grupo de pesquisa composto por docentes e alunos (graduação e pósgraduação), oferendo oportunidade de convivência, aprendizado e crescimento, pessoal e profissional, dos bolsistas.

A incorporação dos bolsistas nas atividades do Grupo de Pesquisa do Laboratório de Ensaios Não Destrutivos da FEAGRI (LabEND) teve por objetivos:

-Formação básica em Pesquisa Científica, com foco nos diferentes aspectos que são envolvidos: hipótese, metodologia, análise de resultados;

-Treinamento para uso de equipamentos de ultrassom (USLab, Panametrics) e de software de geração de imagens (tomografia ultrassônica);

-Formação básica em conceitos que envolvem técnicas de propagação de ondas e aplicação dessas técnicas na caracterização, classificação de diferentes tipos de materiais e tomografia ultrassônica para inspeção de árvores e peças estruturais;

-Incorporação em atividades experimentais envolvendo a utilização dos equipamentos de ultrassom e geração de imagens;

-Treinamento em atividades de organização de dados e geração de planilhas.

\section{Resultados e Discussão}

Através de treinamento oferecido por alunos de graduação e pelo técnico do laboratório, foi possível obtenção de conhecimento básico sobre conceitos e utilização dos equipamentos de ultrassom (Figura 1), utilizados no LabEND para caracterização e classificação de materiais, assim como na inspeção de obras e árvores.

O equipamento USLab foi utilizado na realização de ensaios em peças roliças de eucalipto, referentes a pesquisas em nível de mestrado e doutorado, que têm como objetivo classificação da madeira. Das peças roliças foram obtidos corpos de prova, que foram usados para a obtenção da densidade do material.

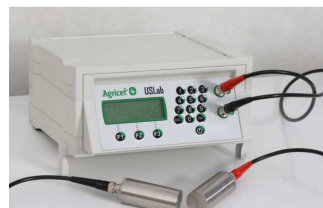

(a)

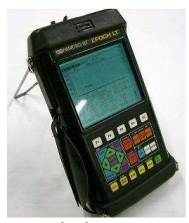

(b)
Figura 1. Equipamentos de ultrassom (a) USLab e (b) Panametrics.

Em relação a caracterização de materiais, houve participação em ensaios relativos a projeto de doutorado de aluna da Universidade Federal de Mina Gerais, em que foi utilizado o equipamento Panametrics para a obtenção de parâmetros acústicos de poliedros de diferentes espécies de madeira.

Alunos de mestrado, que possuem projetos voltados para elaboração de metodologia para inspeção e avaliação de risco de queda de árvores, foram responsáveis por treinamento para uso de software de geração de imagens (Imagewood) e sobre princípios básicos da tomografia ultrassônica.

Os dados obtidos nos diferentes tipos de ensaios foram utilizados em atividades de treinamento de organização de dados e geração de planilhas para análises dos resultados das pesquisas.

\section{Conclusões}

A inserção de alunos do ensino médio no âmbito universitário foi de grande valor para seu crescimento pessoal e profissional, pois permitiu seu contato com os mais diferentes níveis de estudantes e de pesquisas, o que ampliou seus conhecimentos e reduziu 0 distanciamento do ambiente escolar e da vida universitária. Ademais, o projeto representou importante porta de entrada para aquisição de conhecimento e introdução do aluno no meio científico.

\section{Agradecimentos}

Ao CNPq pela bolsa de estudo de Iniciação Científica, à FEAGRI e ao LabEND. 